DOI: https://doi.org/10.5007/1980-3532.2016n16p55

\title{
As estratégias e ações do movimento Porto do Capim em Ação à luz do conceito de heterotopia de Foucault
}

\author{
The strategies and actions of the Porto do Capim in Action \\ movement in light of the concept of heterotopia of Foucault
}

\author{
Irley David Fabrício \\ Universidade Federal da Paraíba \\ Mestrando em Comunicção e Culturas Midiáticas (UFPB) \\ irleydavid@gmail.com
}

\begin{abstract}
Resumo: Objetiva-se, por meio deste texto, lançar uma compreensão um pouco mais aprofundada das lutas travadas pelos movimentos sociais que vêm sendo protagonizados no início do século XXI, especificamente o movimento Porto do Capim em Ação, na medida em que possamos aproximar e compreender as estratégias e ações desse movimento à luz do conceito de heterotopia de Foucault, dos espaços outros, e de autores críticos da pós-modernidade, a exemplo de Soja e Valverde, que também debruçam-se sobre tal conceito, ampliando o seu entendimento e sua possível aplicabilidade. Para alcançar tal objetivo, foi necessário uma pesquisa bibliográfica, com leitura de relatórios, de artigos e de obras que tratassem do tema. Considera-se que as estratégias e táticas de lutas empreendidas pela comunidade do Porto do Capim se encaixam nesse quadro teórico como enclaves insurgentes, erráticos, no sentido de luta pela moradia; de luta pelo território; de resistência aos interesses do poder dominante em eliminar a diferença, o outro; e, por fim, no sentido de resistência à padronização normativa dos espaços urbanos.
\end{abstract}

Palavras-chave: Heterotopia. Porto do Capim. Movimentos sociais. Gentrificação social. Utopia.

Abstract: We aim, through this text, a slightly deeper understanding of the struggles waged by social movements and expressions that have been perpetrated in the early twenty-first century, specifically the port movement of grass in Action, to the extent that we can approach and understand the strategies and actions of this movement in the light of the concept of Foucault's heterotopia, other spaces, and critical authors of postmodernity, like soybean and Valverde, who also are occupied with the concept, expanding its understanding and its possible applicability . To achieve this goal, a literature search was necessary, read reports, articles and works that addressed the issue. We believe that the strategies and tactics of struggle undertaken by the Port of grass community fit into this theoretical framework as enclaves insurgents, erratic, to struggle for housing; fight for territory; resistance to dominant power to eliminate the difference, the other; and finally, in the sense resistance normative standardization of urban space.

Keywords: Heterotopia. Port grass. Social movements. Social gentrification. Utopia.

Originais recebidos em: 15/02/2017

Aceito para publicação em: 01/11/2017

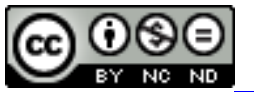

Este trabalho está licenciado sob uma Licença Creative Commons Atribuição-Uso Não-Comercial-Vedada a criação de obras derivadas 3.0 Unported License

Revista Em Debate (UFSC), Florianópolis, volume 16, p. 55-72, 2016. ISSNe 1980-3532 


\section{Introdução}

O nosso interesse em analisar, ou melhor, aproveitar as análises de Foucault (1967) a respeito das heterotopias, bem como dos autores pós-modernos, como Valverde e Soja, além de outros, que aqui serão discutidos, está justamente em buscar uma compreensão aprofundada das lutas travadas pelos movimentos e protestos sociopolíticos que vêm sendo protagonizados no início deste século, especificamente o movimento Porto do Capim em Ação. Parte-se do pressuposto de que tais estratégias e táticas de lutas poderiam se encaixar nesse quadro teórico como enclaves insurgentes, no sentido de luta pela moradia; de luta pelo território; de resistência aos interesses do poder e grupos dominantes em eliminar do espaço "outro" os indesejados em nome de um suposto desenvolvimento cultural e econômico da cidade e da padronização sacralizada dos espaços urbanos.

Para alcançar o objetivo deste trabalho, foi necessário adotar um procedimento metodológico que fosse capaz de fornecer dados a respeito do tema e da realidade da comunidade do Porto do Capim. Assim, tomou-se como fonte de pesquisa algumas obras, artigos, relatórios e as redes sociais. No caso desta última, optou-se por fazer uma sucinta pesquisa no perfil da comunidade Porto do Capim no Facebook, considerando que foi uma das redes sociais mais utilizada no processo de luta da comunidade, que pudesse apresentar a linha de resistência ou contestação da comunidade, sempre, portanto, buscando entendê-la à luz de conceitos relacionados à heterotopia. Nesse mesmo sentido, buscou-se compreender a exposição do projeto Memórias Ribeirinhas, o qual, ainda que não tenha sido fruto exclusivo da comunidade mas produto de correlações de forças distintas e afirmativas, em nossa visão, desperta a visão da sociedade e de entes públicos sobre a importância da comunidade, bem como de sua identidade e cultura.

Quanto à estrutura do trabalho, no primeiro momento buscamos apresentar o conceito de heterotopia na ótica do próprio autor que o concebeu, Foucault (1967), e também na ótica de pensadores, que, não satisfeitos com a definição e delimitação dada por Foucault, buscou ampliá-lo, de modo que fosse possível aplicá-lo em outros contextos e situações. Selecionamos o conceito de heterotopia por considerá-lo essencial para este estudo, pois é por meio dele que buscamos compreender a estratégias e ações do movimento do Porto do Capim em Ação como atos de resistência, poder e 
renovação social, na medida em que busca questionar a ordem social, política e econômica constituídas, fazer refletir sobre o diferente, e, por fim, inovar e renovar os espaços sacralizados, normativos.

Em seguida foi apresentada a história do surgimento da comunidade Porto do Capim, que teve início, ali, às margens do Rio Sanhauá, por volta da segunda metade do século XX. Para além da simples ocupação do antigo Porto do Capim, a comunidade criou raiz com o lugar, com o rio e com o mangue, fazendo desse território o seu espaço de vida e de afeto. Não satisfeitos com a presença dos ribeirinhos às margens do Rio Sanhauá, palco de fundação da capital paraibana, segmentos da população pessoense começaram a minar, ainda em 1990, a ideia de remoção da comunidade, aspirando outros interesses para aquele território.

Iniciou-se, desde então, estratégias e ações para remover a comunidade daquele local, processo que tem sido, de acordo com as visitas técnicas realizadas pela equipe técnica do Centro de Referência em Direitos Humanos da UFPB na comunidade do Porto do Capim, veementemente assinalado como higienização social. Processo pelo qual se busca deslocar usuários ou residentes com menor poder econômico de uma dada rua, mancha urbana ou bairro para outro local, em contrapartida da entrada de usuários com maior poder aquisitivo.

Por fim, são apresentadas as estratégias e táticas de luta da comunidade para resistir aos interesses da ordem dominante em eliminá-la de seu local habitado tradicionalmente há mais de 70 anos. As estratégias e ações empreendidas pelos ribeirinhos do Porto do Capim são vistas, aqui, como ato de resistência às diversas formas de racionalidade instrumental moderna. A heterotopia aqui cumpre papel importante na renovação do pensamento social sobre os espaços urbanos e, sobretudo, quem deve ou não ocupá-los.

\section{Heterotopia: os espaços outros}

Cumpre mencionar que não é o nosso objetivo exaurir o conceito de heterotopia, seja este em Foucault, Valverde ou Soja. Pelo contrário, objetiva-se fornecer uma noção a respeito desse conceito, de modo que se consiga compreender a visão dos autores sobre tal termo e a sua efetiva aplicabilidade no presente trabalho. 
A segunda metade do século XX foi bastante produtiva para Michel Foucault. Foi a época em que o autor escreveu o proeminente texto Espaços Outros, um abre alas para pensar e repensar temas como cidade, espaço e relações de poder em um mesmo ambiente e para mostrar que o espaço do "outro" sempre foi esquecido pela cultura ocidental. Trata-se de um texto breve e, ao mesmo tempo, denso, como tantos outros de Foucault. Ele foi escrito na Tunísia, especificamente no ano de 1967, e proferido como conferência no Círculo de Estudos Arquitetônicos da época. Embora proferido em tal evento, o autor só permitiu a publicação da obra em 1984, meses antes de sua morte.

Para esclarecer melhor, convém ressaltar que quando o autor fala sobre o espaço do "outro" esquecido pelo ocidente ele quer dizer que a civilização ocidental ${ }^{1}$ praticamente nunca poupou esforços para buscar a unicidade, a universalidade, eliminando, portanto, o outro, o indesejado, ou o espaço deste, ou seja, tudo aquilo que é diferente ou possa oferecer risco ao que foi previamente estabelecido pelo poder dominante e que possa de alguma maneira afetar a ordem social, política, cultural ou econômica de uma determinada sociedade.

É no texto Espaços outros que é concebido o conceito de heterotopia, ideia central do texto, fruto da reflexão do autor sobre os espaços que irrompem em sociedades cuja ordem globalizante seja a homogeneização social ou a implantação de um sistema social sem levar em consideração as diferenças ou os outros espaços que em algum momento aparecem, gerando crise, tensão ao que foi previamente dado como padrão. Além de gerar tensão, as heterotopias dessacralizam e, em até certa medida, renovam aquilo que está enraizado no tecido social, promovendo novos sentidos e novas configurações nos espaços sociais. Para Foucault (1967) elas ameaçam e inquietam porque minam secretamente a linguagem, porque impedem de nomear isto e aquilo, porque quebram os nomes comuns, porque de antemão arruínam a sintaxe. Continua o autor, a heterotopia pode ser entendida como:

Espaços de crise e de desvio, ordenações concretas de lugares incompatíveis e tempos heterogêneos, dispositivos socialmente isolados, mais facilmente penetráveis e, por fim, máquinas concretas de imaginação cujo papel é o de criar um espaço de ilusão que denuncia, como mais ilusório ainda, o espaço

\footnotetext{
${ }^{1}$ Trata-se de um termo comumente usado para se referir a um legado cultural de normas sociais, valores éticos, tradições, crenças, sistemas políticos, artefatos e tecnologias que têm alguma origem ou associação com a Europa. O termo se aplica a países cuja história tem ligações estreitas com a emigração dos habitantes de países europeus mas que não é restrita a esta, tais como os países da América. Disponível em: <https://goo.gl/jni7fV> Acesso em: 17 jan. 2017.
} 
real, todas as colocações no interior das quais a vida humana está compartimentada. (FOUCAULT, 1967, p. 61-62)

Valverde (2009, p. 8) ao se debruçar sobre o texto Espaços outros entende que Foucault, ao falar sobre heterotopia, referia-se ao "dinamismo social, às mudanças, aos confrontos de ideais e à iminência de novas representações" em um mesmo espaço. Continua o pensador.

Foucault parecia acreditar que a transformação da sociedade moderna não
seria possível simplesmente através da troca de ideias realizadas nos fóruns
políticos pré-determinados, mas sim pela visibilidade que o espaço provia a
necessidades e sentimentos que eram combatidos pelo Estado. É a partir
desse princípio [...] que a sociedade contemporânea ainda é lida como espaço
rígido, sacralizado, como se as suas formas e significados fossem totalmente
consensuais. Com isso, o autor apresentou interesse pela ideia de heterotopia
ao procurar uma forma de classificação espacial que valorizava a presença de
múltiplas representações conflitantes em uma mesma área, em um mesmo
espaço. (VALVERDE, 2009, p. 9-10)

Até certo ponto também se pode conceber heterotopia como a inversão direta de utopia. A utopia é entendida por Santaella (2016, p. 247) como a "analogia direta, aperfeiçoada ou inversa com o espaço real da sociedade, mas são essencialmente irreais". Trata-se, portanto, de uma ilusão que busca nos guiar para aquilo que acreditamos ser perfeito. Em outras palavras, a utopia é, nada mais nada menos, uma linha imaginária que nos conduz para a busca de um mundo perfeito, muitas vezes impossível de ser projetado e mantido tal como pensado, pois os espaços são dinâmicos e constantemente se reinventam, assumindo novas significações no tempo e no espaço a partir das ocupações sociais que neles são empreendidas.

A construção de Brasília, capital do Brasil, a título de exemplo, talvez seja o caso mais evidente e amplamente conhecido sobre a incessante busca por uma cidade utópica. A capital do Brasil foi planejada para atender aos anseios de uma ideia cujo objetivo maior foi a busca por uma cidade perfeita, com espaços previamente pensados, refletidos e designados para determinados segmentos e públicos da sociedade, públicos estes, vale ressaltar, com alto poder aquisitivo, já que as condições mínimas para se viver no Plano Piloto assim exigiam, e até hoje exigem. Embora planejada para atender a determinadas utopias, os "espaços outros" de Foucault parecem se fazer representar na realidade da cidade que foi planejada para ser "perfeita", colocando em xeque o ideal daquilo que se esperava.

O crescimento populacional de Brasília foi intenso desde sua construção. Ela foi uma cidade planejada para habitar 500 mil habitantes, um número muito 
pequeno comparando com a sua população de hoje em dia. Seu número de habitantes nos dias de hoje é de 2,6 milhões. Muitos migrantes de outras regiões do Brasil começaram a migrar para a capital em busca de trabalho, o que ajudou muito para esse enorme crescimento demográfico. Porém, não eram todos que tinham condições de viver no Plano Piloto, ou seja, o plano onde tudo era mais caro. A maioria desses migrantes, ajudaram a construir a cidade, ou seja, eram trabalhadores, e estes acabavam morando nas chamadas cidades satélites, que eram periferias, mas muito conhecidas como um local onde as pessoas apenas dormiam, já que passavam o dia trabalhando no Piloto. As cidades satélites, ao contrario de Brasília, não foram planejadas. Foi basicamente um erro e descuido nos planos de Lucio Costa. As cidades satélites passaram a serem consideradas favelas e as pessoas indesejadas. (ISABELLA, 2012, p. 4)

Hoje, são cerca de 31 cidades satélites no entorno do Plano Piloto. Em geral, essas cidades são denunciadas como abandonadas pela administração pública, o que significa que realmente as cidades satélites, e as populações que as habitam, muitas vezes sob as piores condições possíveis, são vistas não como prioridades para os planos de desenvolvimento urbano do governo, mas como um problema para a cidade. Negar ou dificultar o direito à moradia, à cidade, à cultura, ao lazer, e a outros direitos básicos essenciais à dignidade humana, é suprimir paulatinamente e estrategicamente o espaço do outro.

\footnotetext{
Em relação ao Plano Piloto, são claras e até obvias as diferenças. Não apenas pelo fato de o Plano Piloto ter sido planejado, mas por as cidades satélites terem sido completamente abandonadas. Entrevistados nos disseram que eles são considerados como "indesejados". Hoje, são poucas as cidades satélites que têm infraestruturas para garantir uma vida aos habitantes como o Plano Piloto oferece. Moradias, infraestrutura, as superquadras, hospitais, clubes, colégios, teatros, igrejas, ou seja, espaços públicos em boas condições e espaços de lazer, são coisas que fazem falta para os habitantes das cidades satélites. (ISABELLA, 2012, p. 5)
}

Brasília é o exemplo mais evidente entre utopia e heterotopia na cidade. É importante destacar que essa relação ambivalente entre utopia e heterotopia se apresenta na sociedade de várias formas, nunca da mesma forma, pelo menos essa é a concepção de Foucault (1967), pois para o autor elas fogem da banalidade, daquilo que é normativo. O que é comum, para ele, já tem suas raízes na sociedade, faz parte do cotidiano, não gerando assim renovação.

Foucault (1967) busca ainda apresentar uma espécie de heterotopologia com o objetivo de orientar a reflexão do pensamento sobre as formas em que as heterotopias se apresentam na sociedade. Para ele, por exemplo, os hospitais psiquiátricos e as prisões são exemplos socioespaciais de heterotopias de crise e de desvio. São espaços que refletem a condição de indivíduos que se encontram em estado de crise e de indivíduos 
que se afastam da normas sociais, das leis que regulam a sociedade e impõem regras para o "bom" comportamento dos cidadãos, por isso devem ser suprimidos da cidade "utópica", da cidade que busca constantemente a utopia, em todas as suas dimensões.

Embora a heterotopologia apresentada por Foucault, que aqui não foi exaurida, considerando-se que as outras categorias ${ }^{2}$ tratadas pelo autor não interessavam a este trabalho, sirva-nos em parte para orientar o nosso pensamento sobre as heterotopias no interior de uma sociedade, ela ainda não aparenta ser tão clara assim, talvez fizesse mais sentido à época em que o autor escreveu o texto Espaços outros.

As prisões e as clínicas psiquiátricas ainda existem na realidade do vigente século, fortalecendo o argumento de Foucault sobre a existência de espaços outros para aqueles que desviam-se das normas sociais e para aqueles que entram em estado de crise psíquica, não tendo, por essa questão, mais utilidade para as posições pré-estabelecidas na sociedade, voltadas para o trabalho, para a escola, para a faculdade, etc. Entretanto, o comportamento de crise e, sobretudo, de desvio, em si, como práticas heterotópicas não aparenta ser tão incomum assim, pelo menos sob o ponto de vista da violação das atuais regras sociais no contexto do século XXI.

É sabido que os desvios entram em rota de colisão com as regras sociais, mas pelo seu caráter rotineiro, ganha certo aspecto de naturalidade e de normatividade, como se esses espaços de práticas não gerasse tanto desconforto assim, fazendo parte, por isso, do cotidiano.

Além disso, o espaço do outro, pelo menos na concepção de espaço como algo físico, a exemplo novamente da clínica psiquiátrica e das prisões, não é tão incomum assim, pelo menos na realidade do início deste século, o que torna a ideia de Foucault sobre heterotopia um pouco hermética, dificultando aplicá-la, portanto, em outros contextos e circunstâncias sociais.

Pelas razões expostas, especialmente com relação à ligação entre heterotopia e não causalidade, a ideia de heterotopia concebida por Foucault recebeu bastantes críticas, devido à falta de clareza nos seus princípios básicos e, também, exemplos.

Foi a partir das críticas pós-modernas que a ideia de heterotopia foi recuperada, sem entretanto perder algumas características de sua origem, como a própria relação entre heterotopia e normatividade, ganhando maior interesse e destaque em estudos que

\footnotetext{
${ }^{2}$ Além das heterotopias de crise e de desvio, Foucault, no texto Espaços outros, concebe outras, como a heterotopia de compensação, e outras. Disponível em: 〈https://goo.gl/mBDbZM> Acesso em: 23 jan. 2017.

Revista Em Debate (UFSC), Florianópolis, volume 16, p. 55-72, 2016. ISSNe 1980-3532
} 
envolvem as táticas de ações heterotópicas em movimentos e manifestações sociais ${ }^{3}$ e estudos sobre o espaço, seja este material ou imaterial. Um dos exemplos que podemos vislumbrar a heterotopia como ato de luta é a ocupação do espaço público ou privado como resistência às regras atualmente vigentes, que proíbem, por exemplo, a ocupação, estabelecendo de pequenas a severas penalidade para quem assim infringir.

A pichação também poderia se enquadrar como ato heterotópico, na medida em que provoca desconforto na sociedade e constrói novos regimes de visibilidade e de expressão política. Trata-se de uma espaço heterotópico que renova o tecido social, questionando o que está dado como certo, como socialmente aceito. Tem razão Valverde (2009) quando afirma que Foucault acreditava que a transformação da sociedade não seria possível simplesmente nos fóruns políticos pré-determinados, mas sim pela visibilidade que o espaço provia a sentimentos e necessidades que eram combatidos pelo Estado. Pichação é considerado crime pela lei penal vigente, com pena de 3 meses a 1 ano de detenção, além de multa.

Um dos principais críticos à ideia de heterotopia de Foucault foi Edward Soja (1940-2015). Para Soja (1995) cabia aos espaços heterotópicos a renovação do olhar moderno sobre o espaço urbano. Para ele, a heterotopia não está relacionada somente com os espaços de crise psíquica, tal como concebido e defendido por Foucault, mas, principalmente, com os espaços de resistência, os quais lutam contra às diversas formas de racionalidade instrumental moderna.

\section{O surgimento da comunidade do Porto do Capim}

A comunidade do Porto do Capim está localizada onde, em 1585, começou a ser edificada a capital da Paraíba, João Pessoa, a então, na época, cidade de Nossa Senhora das Neves. Local escolhido pelos colonizadores por sua boa localização para controle da foz do Rio Paraíba, então em disputa com outros povos, a exemplo dos franceses e holandeses. Essa área, conhecida amplamente como antigo Porto do Capim ou Porto do Varadouro, situa-se às margens do Rio Sanhauá, afluente da margem direita do Rio Paraíba e ocupa a parte baixa do bairro do Varadouro. Na parte baixa da cidade, encontravam-se os prédios da alfândega, os armazéns do Porto e as casas comerciais

\footnotetext{
${ }^{3}$ Ver, por exemplo, o estudo da pesquisadora Tatiana Ramos sobre: "heterotopias urbanas: espaços de poder e estratégias socioespaciais dos sem-teto no Rio de Janeiro. Publicado em 18 de abril de 2012. Disponível em: <polis.revues.org/916> Acesso em: 20 jan. 2017.
}

Revista Em Debate (UFSC), Florianópolis, volume 16, p. 55-72, 2016. ISSNe 1980-3532 
(esses prédios ainda hoje podem ser vistos, embora em estados totalmente deteriorados). Já na parte, segundo Agra (2006), alta localizavam-se as construções administrativas, religiosas e as residenciais de alto padrão. Ao longo dos séculos, o Porto do Capim foi se consolidando como importante polo comercial, voltado para a exportação da produção local, principalmente do açúcar. Essa situação se estendeu até a segunda metade do século XIX, quando, em decorrência de assoreamento ${ }^{4}$ dos rios Paraíba e Sanhauá, provocado pela expansão descontrolada da atividade canavieira e pelo crescimento das cidades às sua margens, a função portuária foi transferida para o município de Cabedelo.

Em decorrência dessa mudança, houve um processo de esvaziamento do Porto do Varadouro, fazendo com que este perdesse a sua condição de centro mercantil, entrando, dessa maneira, em decadência.

Além disso, a expansão do comércio seguiu em direção à cidade alta, em direção às praias. De acordo com Mello (1987) apud Moraes, Maciel, Torres (2000) até a década de 1910, a lagoa do Parque Solon de Lucena não permitia o crescimento da cidade em direção ao litoral. Em 1913, foi realizado o saneamento da bacia da lagoa, permitindo, com isso, a expansão da cidade em direção ao leste e ao sul. Após permanecer por mais de três séculos restrita às margens do rio Sanhauá e à colina (parte alta do Varadouro) onde fora fundada a cidade, o comércio avançou para o leste, em direção às praias, num crescente processo de urbanização que se estende até os dias atuais.

\begin{abstract}
À medida que o projeto do Porto do Varadouro fora sendo abandonado pelo governo federal, iniciaram-se as ocupações da região por trabalhadores braçais e pescadores, os quais, ao tornarem o espaço o local de sua habitação e tendo em vista a ação degradante das obras portuárias, passaram a promover a recuperação progressiva do manguezal. ${ }^{5}$
\end{abstract}

A partir desse processo de esvaziamento e desvalorização imobiliária, a área e as instalações desativadas passaram a ser ocupadas por famílias ribeirinhas e pelos extrabalhadores do Porto do Capim, que se viram desempregados com o encerramento das suas atividades e com a decadência da atividade comercial, que agora seguia em outra direção, a do eixo centro-praia, leste de João Pessoa. Dessa forma, ao longo dos últimos 70 anos, a comunidade se consolidou no local, mantendo forte vínculo cultural com o

\footnotetext{
${ }^{4}$ Processo em que se observa no leito dos rios o acúmulo de detritos, lixo, entulhos, etc. Disponível em: < https://goo.gl/9Kfvv3> Acesso em: 23 jan. 2017.

5 Relatório de Violações aos Direitos Humanos no Porto do Capim. Disponível em: <https://goo.gl/9vTmX6> Acesso em: 23 jan. 2017.

Revista Em Debate (UFSC), Florianópolis, volume 16, p. 55-72, 2016. ISSNe 1980-3532
} 
rio e com o mangue, seja por meio da atividade de pesca e de lazer, seja pela prática de rituais religiosos e festivos que acontecem no local.

Como se vê, a comunidade mantém um processo histórico de ocupação do Porto do Capim e uso de um território tradicional, com largas evidência, inclusive visuais (figuras 1, 2 e 3), sobre a sua importância para a preservação do próprio patrimônio histórico da cidade, assim como para a sua recuperação ambiental.

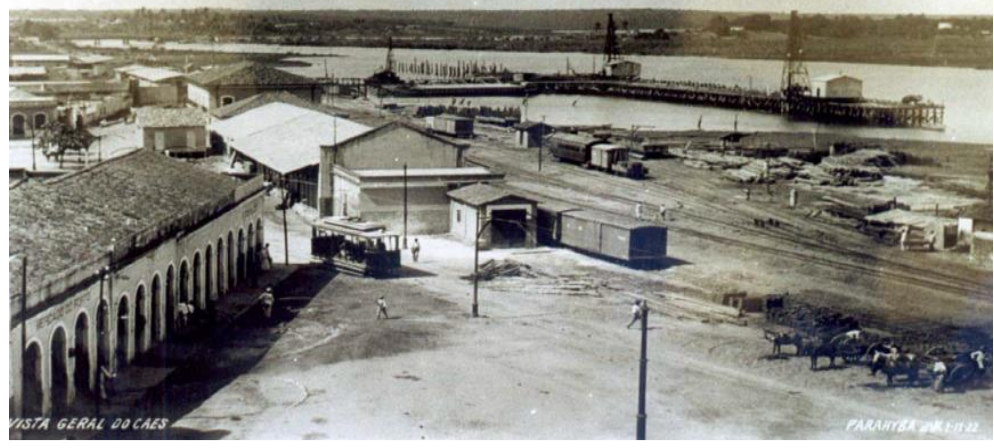

Fig. 1: vista geral do Caés do Porto do Capim. 1922. Fonte: acervo do CHJP.

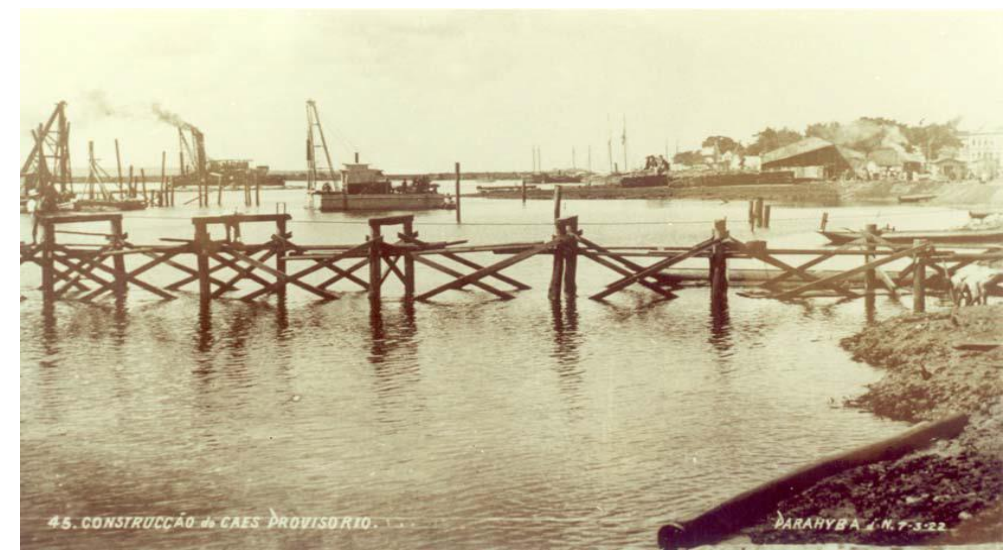

Fig. 2: Construção do Caés provisório. 1922. Fonte: acervo CHJP.

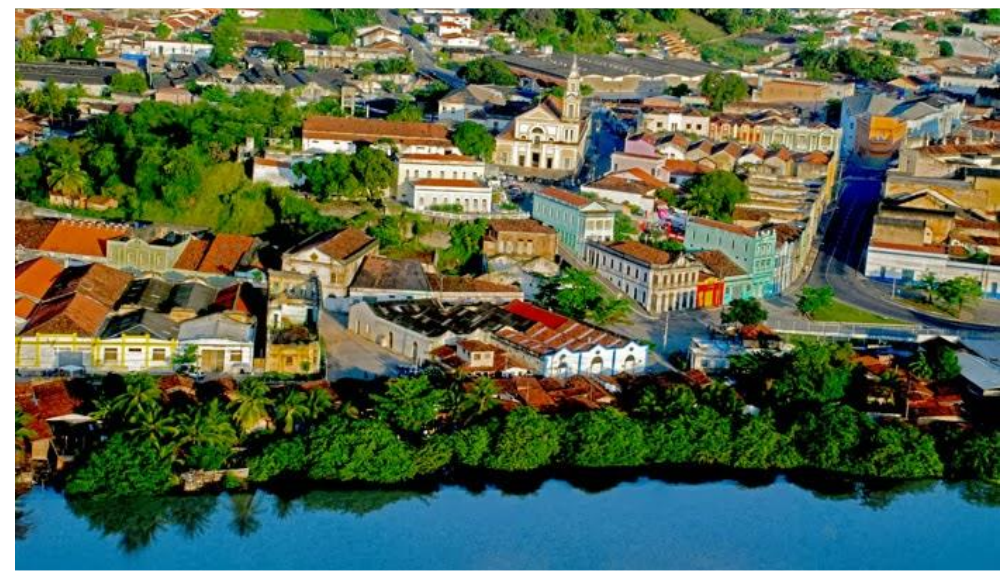

Fig. 3: vista aérea da área atualmente ocupada pela comunidade Porto do Capim. Fonte: galeria de fotos - SETUR/PMJP 
A partir das décadas de 1980 e 1990, conforme Braga e Moraes (2016), o sentimento preservacionista de determinados segmentos sociais pessoenses, a exemplo dos artistas, historiadores, arquitetos e preservacionistas, passaram a ver os ribeirinhos do Porto do Capim como estorvo, uma mácula ao patrimônio histórico da cidade. Foi neste período, ainda segundo os autores, que se iniciou os primeiros passos de orientação técnica e política em busca da transformação das opiniões privadas, dos ditos especialistas no assunto patrimônio histórico, em demandas públicas.

O Decreto $n^{\circ} .9 .484$, publicado em 1982, com apenas dois artigos, já previa a proteção do que eles chamaram de Centro Histórico Inicial, em que já se podia ver certa resistência à proteção das margens do Rio Sanhauá, devido a comunidade que ali já habitava. Conforme Braga e Moraes (2016), a comunidade vive à beira do Rio Sanhauá desde a primeira metade do século XX, estando, portanto, naquela região bem antes da criação da ideia de Centro Histórico de João Pessoa. Desde que essa ideia emergiu no imaginário de determinados segmentos sociais, a comunidade Porto do Capim vem sendo ameaçada de remoção, devido à pretensão, já vastamente anunciada pela Prefeitura Municipal de João Pessoa, de criar, no território habitado por ela tradicionalmente há mais de 70 anos, uma grande arena para eventos (fig. 4).

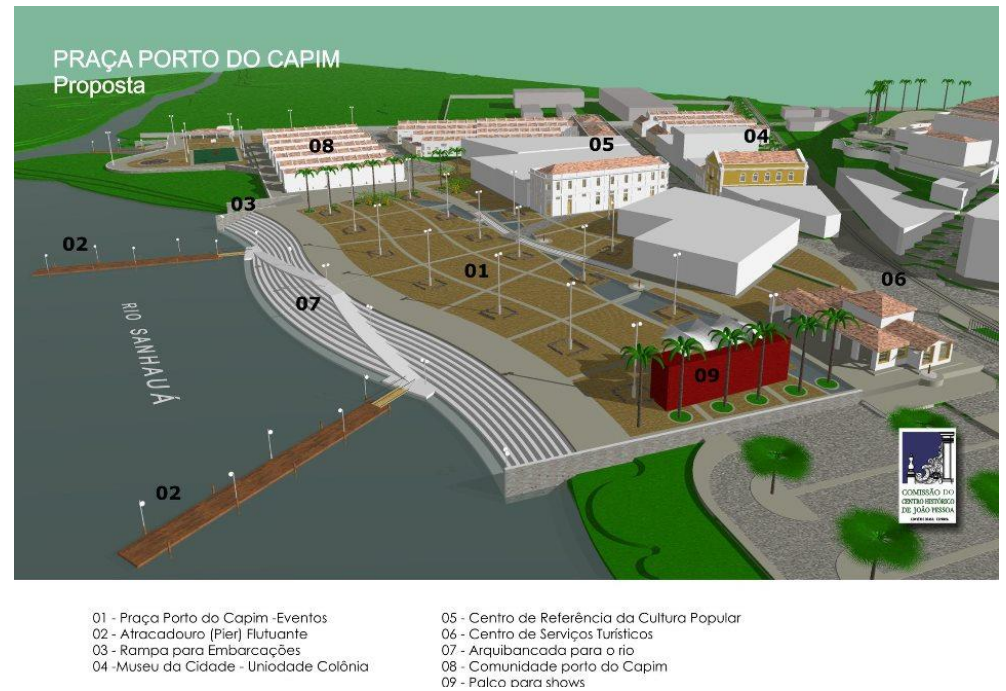

Fig. 4: A arena de eventos que a PMJP pretende implantar no lugar das casas dos moradores e por cima do manguezal. Fonte: <http://centrohistoricojp.blogspot.com/> Acesso em: 25 jan. 2017.

Ainda de acordo com Braga e Moraes (2016), o Projeto de Revitalização do Antigo Porto do Capim previu assistência à população residente nas proximidades da área tomadas como objeto de intervenção. Foi a partir daí que surgiu a ideia de realocar a comunidade em espaço habitacional com unidades mínimas de $49 \mathrm{~m}^{2}$. Entretanto, a 
proposta de realocação não foi muito bem aceita pela comunidade, tendo em vista que afetava de maneira significativa a relação de convivência entre os moradores da comunidade e o território do Porto do Capim. Além disso, afetava economicamente alguns moradores, que tinham, e ainda têm, a pesca e a venda dos peixes como atividades principais para a subsistência familiar.

Alegam-se ainda hoje que o Projeto de Revitalização do Porto do Capim devolveria à sociedade pessoense a histórica relação com o rio, ao recuperar a paisagem cultural de tempos de outrora, como explicitado no discurso da Comissão do Centro Histórico:

\begin{abstract}
Esta intervenção condensa ações que integram e potencializam as linhas estratégicas estabelecidas pelo projeto de Revitalização, que é entender o Centro Histórico como turístico e cultural, um Centro de oportunidade e referência em qualidade de vida. Na perspectiva do cumprimento desse papel estratégico, a intervenção implantada resultará numa requalificação urbana do Antigo Porto do Capim, que deixará de ser área de armazenamento para transformar-se em importante pólo de lazer e diversão da cidade, a partir da utilização de seus espaços públicos para eventos, concentrações e contemplação. De forma associada teremos a requalificação de sua função econômica que, a partir do resgate do vínculo rio/cidade, transformará o rio e o antigo porto em importante núcleo turístico da cidade, com a infra-estrutura necessária ao aproveitamento do turismo histórico-cultural e do eco-turismo, este associado ao estuário do Rio Paraíba. [...] esse processo deverá ainda promover o desenvolvimento social da comunidade do porto do capim, que passará a habitar um novo núcleo habitacional. (CPDCH-JP, 2007, p.11-12)
\end{abstract}

Nessa concepção, que foi muito bem notada por Braga e Moraes (2016), a comunidade do Porto do Capim não faria parte da sociedade, seria uma espécie de entrave, de estorvo, de mácula para a cidade perfeita. A "sociedade", nesse caso, na visão dos mesmos autores, pode ser entendida como as populações de classe média e rica, habitantes de João Pessoa e os visitantes oriundos de outras cidades. Enquanto esses grupos não frequentassem o centro histórico, este estaria sempre fadado ao abandono, como espaço simplesmente destinado ao armazenamento, como bem assinalado pela CPDCH-JP (2007), como se ali não existisse uma comunidade, mesmo que o espaço fosse ocupado por extratos sociais vistos como marginalizados, favelados ${ }^{6}$, pelo então governo local. Seria, na concepção heterotópica, a forma estratégica de eliminar os espaços outros, aqueles espaços que não estão dentro dos "padrões" e não atendem aos interesses de grupos dominantes.

\footnotetext{
${ }^{6}$ De acordo com o Relatório de violações aos direitos humanos do Porto do Capim, elaborado pela equipe técnica do CRDH/UFPB, a PMJP tem caracterizado a comunidade como "favela", "comunidade descaracterizada" e "inquilinos sem raiz no local". Disponível: <https://goo.gl/9vTmX6> Acesso em: 27 jan. 2017.
}

Revista Em Debate (UFSC), Florianópolis, volume 16, p. 55-72, 2016. ISSNe 1980-3532 
Scocuglia também registrou a situação da comunidade Porto do Capim, que está esperando atuação do governo há mais de 10 anos. O que parece é que o governo municipal não tem interesse em ajudar a comunidade, mas sim eliminá-la de modo estratégico, a começar pela omissão de direitos essenciais à dignidade humana.

\begin{abstract}
Assentada em área de patrimônio da União, a favela Porto do Capim é caracterizada como uma invasão, ou seja, ocupação ilegal e irregular. Apesar desta situação todos os entrevistados em nossas pesquisas reclamaram o direito de propriedade de seus imóveis, segundo eles, construídos à custa de muitos sacrifícios. São, na maioria, imóveis próprios inseridos na área próxima ao mangue, alguns ocupando o trecho já parcialmente urbanizado com arruamento e coleta de lixo, construídos em alvenaria, com água encanada e energia elétrica, alguns com linha telefônica, porém sem esgotamento sanitário. Entretanto, os imóveis localizados por trás desta rua principal, foram construídos diretamente sobre o mangue, mediante aterros sucessivos e são mais precários, constituídos por materiais diversos, como restos de madeiras, papelão, taipa, cobertos com palha, entre outros improvisos. (SCOCUGLIA, 2010, p. 80)
\end{abstract}

\title{
Heterotopias no movimento Porto do Capim em ação
}

Com a finalidade de resistir enfaticamente aos interesses do poder dominante já previamente mencionados, alguns grupos políticos passaram a se organizar dentro da comunidade Porto do Capim. Um dos grupos com maior representação e liderança na comunidade foi e continua sendo a Associação Mulheres do Porto do Capim ${ }^{7}$

Combater o discurso dominante de que a comunidade do Porto do Capim é uma favela, um estorvo para a sociedade pessoense, que visava, nada mais nada menos, persuadir a opinião pública no sentido favorável ao Projeto de Requalificação do Antigo Porto do Capim ${ }^{8}$, foi uma das primeiras e várias ações estratégicas da Comunidade Porto do Capim, ao exibir, junto com a Casa do Patrimônio de João Pessoa, a exposição Memórias Ribeirinhas ${ }^{9}$. É assim, de acordo com Braga e Moraes (2016, p.21), que o catálogo de exposição traduz um pouco do cotidiano da comunidade Porto do Capim:

\footnotetext{
${ }^{7}$ A Associação de Mulheres do Porto do Capim foi fundada em 2013, no seio da Comissão Porto do Capim em Ação, grupo que se formou em 2011 como força político-comunitária do Porto do Capim. Disponível em: < https://goo.gl/9vTmX6> Acesso em: 28 jan. 2017.

${ }^{8}$ Importa observar, de acordo com a equipe técnica do CRDH/UFPB, que a caracterização pela prefeitura dos usos atuais do espaço por parte dos moradores do Porto do Capim, tanto em palestras para propagandear o projeto, como também em documentos públicos, demonstra o preconceito de classe subjacente à ideia de substituição das moradias pela implantação de uma arena de eventos focados no turismo negocial. Uso de termos e expressões têm sido utilizado pela PMJP para desvalorizar os ribeirinhos, como já mencionado, e só pode ser entendido à luz da leitura do interesse econômico. Disponível em: <https://goo.gl/9vTmX6> Acesso em: 28 jan. 2017.

${ }^{9}$ O Memória Ribeirinhas foi exibido em setembro de 2011. Disponível em: 〈http://migre.me/uulVY> Acesso em: 28 jan. 2017
}

Revista Em Debate (UFSC), Florianópolis, volume 16, p. 55-72, 2016. ISSNe 1980-3532 
Existe um lugar em João Pessoa onde o quintal de casa é um rio, o apito de um trem faz parte do dia-a-dia e onde, de tempos em tempos, as pessoas se arrumam, se enfeitam e fazem ensaios para os festejos em homenagem aos santos juninos. Existe um bairro na nossa querida cidade onde os vizinhos põem cadeiras na calçada nos fins de tarde e falam da vida alheia, dos namoros que começaram ou terminaram, dos sonhos para o futuro dos filhos e sobre o último capítulo da novela das sete. Na esquina da rua Dom Vital, apostas são feitas no jogo de dominó no meio das risadarias das velhas amizades regadas a cerveja. Em frente ao bar da Vera, um rapaz exibe a caixa de som do seu carro com os últimos hits do momento. Descendo a ladeira São Pedro Gonçalves, crianças trazem os últimos trocados conseguidos com os turistas que vêm visitar o antigo hotel Globo e apreciar do terraço a vista panorâmica do rio Sanhauá, aquele mesmo rio que é o quintal de muita gente e que outrora foi palco de histórias de potiguaras, africanos, holandeses e portugueses. Todos os anos acontece, neste bendito lugar, a procissão de Nossa Senhora da Conceição. Dia oito de dezembro, os moradores se reúnem em frente à Igreja São Pedro, descem para o porto, levando muitos barcos para o Sanhauá e dali, do velho atracadouro, partem para a Ilha da Santa, com adornos, flores, velas e cantos. Ouve-se o barulho de fogos e, por vários cantos do centro da cidade, sabe-se que aquele povo está em festa. No passado remoto e no presente sofrido, poucas áreas de João Pessoa concentram em um mesmo espaço tanta vida, tanta história e diversidade cultural como o Porto do Capim. Com sua convivência diária junto do rio, suas lorotas de pescador, seus pastores evangélicos de voz forte e Bíblia na mão, seu artesanato de biscuit, seu comércio miúdo, de dose de cachaça, de quilo de arroz, de saco de pão, o cotidiano desses moradores oferece, sem exigir nada em troca, mais beleza à paisagem do Centro Histórico da capital paraibana, tombado em 2007 como Patrimônio Cultural do Brasil.

O IPHAN ${ }^{10}$, orgão responsável pela gestão do Projeto de Revitalização do antigo Porto do Capim, que faz parte do PAC - Programa de Aceleração de Crescimento, antes resistente à comunidade e a favor da revitalização, reconheceu que foi educada pela comunidade Porto do Capim a partir da exposição Memórias Ribeirinhas.

Ela abriu nossos olhos, aflorou todos nossos sentidos, para perceber que o que tínhamos como proposição inicial era a domesticação da memória comunitária em um espaço preservacionista meramente contemplativo, que o importante para eles não é o que eles "faziam”, suas histórias não poderiam ser congeladas em um asséptico contexto museógrafo. O que importa é o que eles fazem no presente para garantir a vitalidade da identidade ribeirinha em meio a um centro histórico forjado com pobres narrativas preservacionistas. Eles são um museu vivo e rico de referências culturais importantes para compor outro tipo de política de reconhecimento e salvaguarda do centro histórico de João Pessoa. Suas histórias de vida transformaram a perspectiva política do Memórias Ribeirinhas e de parte da equipe de trabalho do Iphan que passou a propor e agir dentro da instituição de modo diferente quando o assunto era "revitalização do centro histórico de João Pessoa". (BRAGA e MORAES, 2016, p. 48)

\footnotetext{
${ }^{10}$ É importante destacar que, na época, a aquipe técnica do Instituto do Patrimônio Histórico e Artístico Nacional da Paraíba estava dividida, assim, parte era a favor da permanência da comunidade em seu território, razão pela qual apoiaram o projeto Memórias Ribeirinhas.
}

Revista Em Debate (UFSC), Florianópolis, volume 16, p. 55-72, 2016. ISSNe 1980-3532 
Trata-se de uma ação heterotópica por dois grandes motivos: primeiro porque busca combater, suspender, neutralizar ${ }^{11}$ o discurso dominante de que ali, no Porto do Capim, seja uma favela, lugar propenso à criminalidade, apresentando o cotidiano e a vida dos riberinhos que ali residem há mais de 70 anos, resgatando o patrimônio cultural e histórico da cidade e, principalmente, recuperando o meio ambiente, que outrora foi totalmente desgastado. Para além disso, o projeto apresenta, com riqueza de detalhes, a comunidade do Porto do Capim à luz dos olhares dos próprios moradores. É o discurso do "outro" neutralizando o discurso do "poder dominante"; segundo porque renova o pensamento social, lança um novo olhar sobre a sociedade, desconstruindo e desestabilizando ideias sacralizadas de que o outro tem que se submeter às imposições do poder dominante, abrindo mão, muitas vezes, de seu território e de sua identidade em favor de projetos que objetivam eliminar tão somente o diferente na tentativa incansável de busca da cidade utópica e do capital, com seus padrões espaciais previamente estabelecidos dentro de uma lógica social, cultural e mercadológica.

O projeto Memórias Ribeirinhas promoveu não só a “desestabilização ideológica da Superintendência do IPHAN na Paraíba e em novos rearranjos de hegemonias e marginalidades nos critérios de execução de políticas públicas" (BRAGA, MORAES, 2016, p. 49), mas também mobilizou a sociedade civil. Vários segmentos da sociedade civil aderiram à causa do movimento do Porto do Capim, manifestando-se a favor da resistência cultural dos ribeirinhos e de sua permanência no local, a exemplo do projeto de extensão da UFPB “Abrace Porto do Capim”, representado por Araci Almeida, que lançou manifesto ${ }^{12}$ em que diversos especialistas se posicionaram a favor de um projeto democrático e mais participativo, rejeitando, portanto, a ideia de remoção da comunidade; do CRDH/UFPB, que realizou visitas técnicas com o objetivo de ouvir a comunidade e investigar as denúncias de violações aos direitos humanos. As visitas resultaram no Relatório de Violação aos Direitos Humanos do Porto do Capim ${ }^{13}$; e da Associação Brasileira de Antropologia, que emitiu, em 2014, nota de repúdio ao projeto que busca remover a comunidade do Porto do Capim.

\footnotetext{
${ }^{11}$ Para Foucault, existiriam certos espaços que, devido a concentração de atores e de significados, seriam caracterizados pela inversão, suspensão ou neutralização da ordem oficial (VALVERDE, 2009, p.10)

${ }^{12} \mathrm{O}$ manifesto em apoio à comunidade Porto do Capim. Disponível em:

<http://www.capacidades.gov.br/blog/detalhar/id/91/post/614/param/ativos> Acesso em: 28 jan. 2017.

${ }^{13}$ Disponível em:

<https://issuu.com/crdhufpb/docs/relat_rio_porto_do_capim/1?e=16512531\%2F12071048> Acesso em: 28 jan. 2017.
}

Revista Em Debate (UFSC), Florianópolis, volume 16, p. 55-72, 2016. ISSNe 1980-3532 
A Associação Mulheres Porto do Capim também criou, em 2012, a página \#Porto do Capim em Ação ${ }^{14}$ no Facebook como estratégia para dar visibilidade ao movimento do Porto do Capim e também para combater o discurso tão propagado pela PMJP de que ali seja espaço de marginalidade e que, por isso, os moradores dali devem ser forçosamente removidos para que, no lugar de intervenção, seja possível construir um lugar frequentável pela "sociedade". O que mais parece é que os gestores públicos estão pensando o projeto separando "quem nós queremos" e "quem nós não queremos" naquele espaço. A página \#Porto do Capim em Ação divulga as ações culturais e artísticas da comunidade como ato político-comunitário, bem como as suas atividades educacionais e comerciais como ato de mobilização e de resistência ao projeto que busca removê-la, apagá-la das bordas da sociedade.

\section{Considerações finais}

O movimento do Porto do Capim em Ação, bem como vários outros movimentos sociais que vêm ocorrendo no início do século XXI, a exemplo do movimento feminista, do movimento operário, do étnico-racial, do ecológico, do semteto, etc., cumpre um papel essencial: questionar a ordem dominante e lutar por uma democracia mais participativa e menos representativa e por uma espacialidade justa, igualitária, em que seja possível reinventar o espaço, seja este material ou imaterial, agregar novos sentidos e valores, mesmo que estes não comunguem com os mesmo "valores" da ordem instituída.

É preciso ampliar essas possibilidades de luta e de liberdade, pensar em horizontes que garantam que o outro possa aparecer, lutar, pertencer à sociedade, que possibilitem que novos espaços sejam criados, de modo autônomo, de heterotopias urbanas, das fissuras sociais.

Com freqüência, nas bordas do sistema podem ser observados sinais e evidências não só de reapropriação e ressignificação de espaços públicos [como o caso do Porto do Capim], como também de criativa conversão de espaços improváveis em palcos improvisados de algum tipo de cena pública, menos ou mais inclusiva, especialmente por parte de jovens. Isso "compensa" a negatividade das tendências observáveis? Decerto que não. São, essas ramificações, suficientes, por si sós, para reverter o quadro? Por enquanto não passam de reações interessantes, mas não muito mais do que isso. Mas são, também, sintomáticas - no sentido de que a tese do "conformismo

\footnotetext{
${ }^{14}$ Disponível em:

<https://www.facebook.com/PortoDoCapim/info/?entry_point=page_nav_about_item\&tab=page_info>

Revista Em Debate (UFSC), Florianópolis, volume 16, p. 55-72, 2016. ISSNe 1980-3532
} 
generalizado" não pode ser absolutizada a ponto de nos cegar para o que se passa "nas nossas barbas", e sintomas de que é justamente nas bordas do sistema e em meio aos escombros que ele produz que devem ser procurados os germes e os maiores potenciais da superação do quadro por todos lamentado. É da luta por autonomia e do apoio a iniciativas que representem ganhos de autonomia que, enfim, se trata... (Souza, 2006, p. 329-330)

É na borda do sistema (grupos e espaços marginalizados) que encontramos as "fissuras sociais", as heterotopias. São, em outras palavras, aqueles espaços que não pertecem totalmente à "sociedade", mas estão ali, sendo percebidos, causando desconforto e ao mesmo tempo renovação na forma de perceber e tratar o diferente, bem como os espaços outros, como no caso do Porto do Capim, que, através de suas táticas de luta e estratégias de ações heterotópicas, renovou a nossa forma de pensar o social, questionou o poder dominante e desestabilizou políticas públicas, dessacralizou ideias sacralizadas, provocou questionamento e reflexões sobre o espaço, sobre a cidade.

É nas heterotopias sociais que encontramos a estratégia fundamental para se avançar na obtenção de ganhos de autonomia, na criação de espaços outros, onde as relações de poder não sejam majoritariamente desproporcionais, opressoras e ditatoriais, mas possam contribuir para a auto-reflexão, autodeterminação e autogestão.

\section{Referências}

AGRA. J. L. Uma contribuição aos estudos sobre a relação de transporte e crescimento urbano: o caso de João Pessoa - PB. Dissertação de mestrado. Programa de pós-graduação em Engenharia Urbana e Ambiental da UFPB. João Pessoa. 2006.

BRAGA, Emanuel Oliveira. MORAES, C. G. S. M. Porto do Capim: lutas e estratégias de existência de uma comunidade ribeirinha do Centro Histórico de João Pessoa. Fonte: 〈http://migre.me/uB7iV> Acesso em: 25 jul. 2016.

CPDCH-JP. Comissão Permanente de Desenvolvimento do Centro Histórico de João Pessoa. 2007. Projeto de Revitalização do Antigo Porto do Capim. João Pessoa.

CRDH Centro de Referência em Direitos Humanos/UFPB. 2015. Relatório de Violações aos Direitos Humanos no Porto do Capim. João Pessoa.

FOUCAULT, M. Des espaces autres. In: Dits e Éricts, tome 2: 1976-1988. Paris: Gallimard, 2001. pp. 1571-1581.

ISABELLA. Brasília, a cidade planejada. Fonte: < http://migre.me/uurRu> Acesso em: 25 jul. 2016.

MORAES, MACIEL e TORRES. História de João Pesssoa e do Porto do Capim. Disponível em: 〈http://migre.me/uu89K〉. Acesso em: 25 jul. 2016. 
RAMOS, T.T. Heterotopias urbanas: espaços de poder e estratégias sócio-espaciais dos Sem Teto no Rio de Janeiro. Fonte: 〈https://polis.revues.org/916> Acesso em: 24 jul. 2016.

SANTAELlA, Lucia. Temas e dilemas do pós-digital: a voz da política. São Paulo. Paulus, 2016. Coleção Comunicação.

SCOCUGLIA, Jovanka B. Cavalcanti. 2010. Imagens da cidade: patrimonialização, cenários e práticas sociais. João Pessoa. Ed. Universitária da UFPB.

SOJA, E. Heterotopologies: a remembrance of other spaces in the citadel of L.A. In: WATSON, S. e GIBSON, K. (ed.). Postmodern cities an spaces. Oxford: Blackwell, 1995.

SOUZA, Marcelo Lopes. O que pode o ativismo de bairro? Reflexão sobre as limitações e potencialidades do ativismo de bairro à luz de um pensamento autonomista. Dissertação de Mestrado em Geografia. Programa de Pós-Graduação em Geografia da Universidade Federal do Rio de Janeiro, 1988.

VALVERDE, F. H. R. R. Sobre espaço público e heteretopia. Acesso em 24 de julho de 2016. Fonte: < http://migre.me/uurJd> Acesso em: 28 jan. 2017. 